\title{
A pesquisa de intervenção psicopedagógica: evidências sobre o ensinar e aprender matemática
}

\author{
Regina da Silva Pina Neves \\ Maria Helena Fávero \\ Universidade de Brasília
}

\section{Resumo}

Adotamos a pesquisa de intervenção psicopedagógica de Fávero (2001a, 2005a) focando os fracionários, os racionais e as competências mediacionais. Trabalhamos com uma estudante do ensino fundamental e graduandos em matemática e pedagogia, em sessões de intervenção articulando: avaliação das competências e dificuldades, planejamento e avaliação da natureza das mediações, ações e notações. A intervenção psicopedagógica engendrou a construção de conceitos e a tomada de consciência das práticas mediacionais. Discutimos sua pertinência na compreensão da mediação, da notação e implicações para a matemática da educação básica e avaliação; as Diretrizes Curriculares das licenciaturas em matemática e pedagogia; a pesquisa na formação de professores..

Palavras-chave: Intervenção psicopedagógica. Matemática. Competências conceituais.

1. Artigo elaborado a partir de tese de doutorado da primeira autora desenvolvida no âmbito do projeto de pesquisa "A atividade mediada no desenvolvimento de competências matemáticas: a construção da lógica do algoritmo da divisão e dos racionais por alunos, professores e licenciandos", coordenado por Maria Helena Fávero (Financiamento: CNPq, Processo 307859/2006-1). 


\section{Psycho-pedagogic intervention research: evidence of mathematics teaching and learning}

We have adopted Fávero's psycho-pedagogic intervention research $\left(2001^{a}\right.$, 2005) focusing on fractional numbers, rational numbers, and meditational competencies. We worked with an elementary school student and undergraduate mathematics and education students in intervention sessions, articulating: the evaluation of competencies and difficulties, planning and evaluation of the nature of mediations, and actions and notations. Psycho-pedagogic intervention engendered the construction of concepts and the awareness of mediation practices. We discuss its relevance in the understanding of mediation and notation, and its implications in elementary education mathematics and evaluation; the curricular guidelines for mathematics and education teacher training undergraduate courses; and research in the context of teacher training.

Keywords: Psycho-pedagogic intervention. Mathematics. Conceptual competences.

\section{La investigación de intervención psicopedagógica: evidencias sobre el enseñar y el aprender de las matemáticas}

Adoptamos la investigación de intervención psicopedagógica Fávero (2001a, 2005a) enfocando los fraccionarios, los racionales y las competencias mediacionales. Trabajamos con una estudiante de educación básica y estudiantes de matemáticas y pedagogía en sesiones de intervención articulando: evaluación de las competencias y dificultades, planificación y evaluación de la naturaleza de las mediaciones, acciones y notaciones. La intervención psicopedagógica engendró la construcción de conceptos y la concientización de las prácticas mediacionales. Discutimos su pertinencia en la comprensión de la mediación, de la notación e implicaciones para las matemáticas de la educación primaria y evaluación; las Directrices Curriculares de las Licenciaturas en Matemáticas y Pedagogía; la investigación en la formación de profesores.

Palabras clave: Intervención psicopedagógica. Matemáticas. Competencias conceptuales. 


\section{Introdução}

As nossas atividades como pesquisadoras nos ensinaram o valor da pesquisa de intervenção com estudantes e professores como fonte de dados sobre vários aspectos da psicologia da educação matemática e sua relação com o ensinar e o aprender da educação básica ao ensino superior. Sabemos que se por um lado o desafio da pesquisa de intervenção centra-se na avaliação dos seus efeitos e eficácia pelo fato de se almejar algum tipo de mudança ou transformação (Fávero, 2007a), por outro lado é este mesmo desafio que, nos impelindo à pesquisa metodológica, garante a riqueza dos dados. Esses por sua vez refinam o método e trazem informações que abrangem desde a evidência entre competências e dificuldades sobre o aprender e o ensinar, até a construção desses processos.

Dito em outros termos, quando nos deparamos, por exemplo, com o fato comum de estudantes do $6^{\circ}$ ao $9^{\circ}$ ano do ensino fundamental (EF) evitar os algoritmos formais da multiplicação e da divisão e lidar com eles como se tratasse de aplicar uma sequência de regras evidenciando a sua não interação com campos conceituais particulares, fica evidente a sua dificuldade de compreensão da lógica do sistema numérico decimal e de sua notação, que deveriam ter sido desenvolvidos nos anos iniciais desse ensino. É desse aspecto que o presente artigo trata: o que nossas pesquisas de intervenção têm nos ensinado sobre o ensinar e o aprender matemática no ensino fundamental anos iniciais (EFAl).

Para assumir o desafio já referido acima, e que permeia a pesquisa de intervenção, temos adotado a abordagem de Fávero (2001a, 2005a, 2007b, 2009, 2011b) que defende "uma integração teórica e metodológica que, ao mesmo tempo em que não perde de vista o sujeito individual e suas atividades internas, não o isola, de modo a levar em conta as atividades comunicativas" (Fávero, 2011b, no prelo):

O desafio desta integração é evidente: ela supõe a criação de situações de natureza interativa para a proposição de atividades que demande dos sujeitos a descoberta dos novos possíveis, como diz Piaget (1976), o que significa atualizar novos conceitos dentro de um campo conceitual dado. Em outros termos, tais situações devem permitir a construção de um novo possível, chegando ao nível da atualização, não apenas concebido como tal pelo sujeito, mas compreendido em suas condições de atualização, o que podemos então denominar de construção de novas competências.

Do ponto de vista metodológico, isso se traduz em desenvolver pesquisas de intervenção em um contexto de interação, isto é, em uma dinâmica sociocognitiva, 
considerando seus efeitos reguladores e como esses se integram ao processo de autorregulação próprio ao indivíduo. A riqueza de dados a qual nos referimos antes é garantida justamente pelo fato de levar em conta, na pesquisa de intervenção, as regulações em situações interativas em uma dinâmica sociocognitiva, considerando as construções cognitivas elaboradas e exploradas por cada indivíduo nessa situação (Fávero, 2007a, 2009).

\section{A pesquisa de intervenção com estudantes e professores do ensino fundamental}

Sabemos que uma das queixas recorrentes de estudantes e professores do $4^{\circ}$ ao $9^{\circ}$ ano do EF diz respeito à resolução de problemas e ao uso das operações aritméticas fundamentais, em especial, no contexto dos números fracionários e racionais. Evidenciam-se, de um lado, estudantes com dificuldades conceituais, de outro, professores com dificuldades em significar as dúvidas conceituais e de planejar ações para superá-las, como mostram inúmeras pesquisas em educação matemática e psicologia da educação matemática (Fiorentini, 2003; Saiz, 1996; Nunes; Bryant, 1997; Fávero; Soares, 2002; Bertoni, 2002; Fávero; Pina Neves, 2007, 2009).

De modo geral, essas pesquisas discutem os baixos níveis de desempenho dos estudantes na resolução de problemas com números fracionários e racionais. Além disso, analisam sua relação com o raciocínio, a comunicação, assim como as relações que esses estabelecem com o conhecimento matemático, construídas mais na aquisição e transmissão de regras do que na construção de significados conceituais. Essa situação também é reincidente nos resultados dos sistemas de avaliação como o Sistema Nacional de Avaliação da Educação Básica (SAEB), a Prova Brasil e o Programa Internacional de Avaliação de alunos (PISA), como mostra Celeste (2008).

Compatível com isso, os Parâmetros Curriculares Nacionais (PCN) alertam que a prática docente não engendra: a compreensão conceitual dos conjuntos numéricos e dos significados das operações aritméticas fundamentais; das relações entre elas, da sua notação, do pensamento reflexivo e da estimativa, sugerindo a necessidade de incentivar a criação de algoritmos alternativos e a análise dos algoritmos formais em situações diversas; a capacidade de investigação dos estudantes, através da verificação e controle de resultados, da atividade coletiva e a criação de estratégias de resolução (BRASIL, 1997).

Os estudos citados anteriormente têm relatado, também, a dificuldade de se formar o professor que ensina matemática (graduação em pedagogia e matemátical apontando a falta de articulação entre teoria e prática na formação inicial e continuada, a desarti- 
culação entre os saberes específicos e pedagógicos, bem como o despreparo dos formadores para empreender essas articulações. Recomendam a necessidade de investigar a formação e a prática docente dos formadores de professores, além de suas implicações na formação dos futuros docentes; investigar a formação dos professores que ensinam matemática de modo integrado; realizar estudos empíricos a partir de novos construtos teóricos que deem conta não só da complexidade cognitiva e afetiva, como também das concepções, crenças e atitudes dos professores.

Compatível com tais questões, Fávero (2004) defende a necessidade de uma proposta teórico-metodológica para o estudo das questões relacionadas ao ensino e aprendizagem da matemática, que considere as contribuições da psicologia do desenvolvimento e suas interfaces com outras áreas: "um modelo psicológico que efetivamente considere o sujeito ativo, construtor de conhecimento" (Fávero, 2004, p. 12). Para tanto, a autora defende dois eixos principais: 1) considerar o desenvolvimento do sujeito e as particularidades deste desenvolvimento; 2) centrar as investigações sobre a aquisição dos conceitos, tendo por método de investigação, o próprio procedimento de intervenção psicopedagógica, o que significa considerar a atividade mediada (ibid, p.13). Tal perspectiva altera significativamente o modo de olhar o sujeito, bem como o conhecimento matemático na prática da pesquisa e na prática em sala de aula, uma vez que considera estudantes e professores em desenvolvimento e partícipes da e na construção dos conceitos matemáticos.

0 presente trabalho fundamenta-se na perspectiva dessa autora e por isso vamos salientar alguns dos seus pontos-chave. Trata-se da defesa de uma articulação entre a psicologia social e a mediação semiótica para a compreensão dos processos desenvolvimentais (Fávero, 2005b, p. 238):

[...] se está considerando o mundo dos objetos e o mundo das pessoas um sistema unificado e que o desenvolvimento se dá por meio das atividades desenvolvidas com os objetos, mediados pelo mundo das pessoas. [...] as ações humanas não são aleatórias; ao contrário, são práticas sociais com um conteúdo que thes dão fundamento.

Assim, na sala de aula, por exemplo, quando um professor faz uso de um discurso particular, "ele introduz novas formas de mediação semiótica, tais como a linguagem escrita, a matemática, as ciências sociais e as naturais e media também concepções particulares a respeito do conhecimento humano e de suas diferentes áreas" (Fávero, 1993, p. 56).

Trazendo para a prática e a pesquisa de intervenção psicopedagógica, essa autora propõe considerar a situação de interação social de modo a evidenciar as regulações 
cognitivas dos sujeitos, sua tomada de consciência em função de um campo conceitual particular (e não de memorização de regras) e a análise desses processos, a partir da produção e dos processos comunicacionais desenvolvidos nessa interação, o que significa considerar três aspectos psicológicos: a formação de conceitos e seu sistema lógico de representação, a tomada de consciência desses conceitos e dessa lógica e a interação social que caracteriza a situação didática na qual são construídos (Fávero, 2005a, 2007a, 2009).

Para tanto, essa autora tem insistido que a avaliação é uma etapa que alimenta a própria intervenção, defendendo que se considerem, para os contextos de ensino e aprendizagem, três tarefas distintas e articuladas: 1) a avaliação das competências dos estudantes/professores e de suas dificuldades, como também a análise da relação entre competências e dificuldades; 2) a sistematização da prática de mediação em termos de objetivos e descrição das atividades propostas, tendo em conta a avaliação e análises referidas; 3) uma análise minuciosa do desenvolvimento das atividades propostas, evidenciando: a/ a sequência de ações dos estudantes; b/ o significado dessas ações em relação às suas aquisições conceituais; c/ a natureza da mediação estabelecida entre o professor e os estudantes (Fávero, 2007b).

Em função disso, temos assumido tal proposta visto que ela tem possibilitado resultados positivos no que diz respeito ao desenvolvimento conceitual de estudantes em situação de dificuldade de aprendizagem em matemática, como mostram os estudos de Fávero e Soares (2002); Bonfim (2006), entre outros. Como também tem se revelado adequada nos processos que visam o desenvolvimento de competências conceituais em profissionais adultos (Pina Neves, 2008; Fávero, 2011a). 0 estudo que relatamos a seguir assume, portanto, essa fundamentação teórico-metodológica e foi desenvolvido de modo a integrar estudante e futuro professor do ensino fundamental.

\section{Participantes da pesquisa}

Participaram do estudo uma estudante de 14 anos do programa de aceleração do EF de escola pública, oito mulheres e dois homens estudantes de graduação em matemática e pedagogia de instituição privada, com idades entre 25 e 34 anos, da cidade de Taguatinga, DF. Sete deles com experiência docente, todos voluntários na pesquisa.

A participação da estudante, indicada pela escola por apresentar baixo rendimento em matemática e histórico de repetência, foi autorizada pelos pais. Sua escolha foi condicionada aos seguintes critérios de inclusão: 1) cursar $06^{\circ}$ ano do EF ou equivalente pelo fato de os estudantes já terem estudado desde $04^{\circ}$ ano os conteúdos curriculares em questão; 2) ser avaliado pelo professor como sujeito em situação de dificuldade de 
aprendizagem em matemática; 3) ser estudante da rede pública, pelo fato de a amostra ser mais significativa se tomarmos como referência a população matriculada no mesmo nível de ensino; e 4) estudar nas proximidades da ISP.

Os professores provenientes do curso de pedagogia foram identificados como: FpE1 e FpE2 e os professores do curso de matemática como: FmE1, FmE2, FmE3, FmE4, FmE5, FmE6, MmE7 e MmE8. Nesse código, F significa feminino, M masculino; $m$ matemática, p pedagogia; E experiência docente e Esm experiência docente; por fim, o numeral funcionou como um contador. A escolha dos professores foi condicionada a dois critérios de inclusão: 1) possuir formação em licenciatura em matemática e pedagogia ou em processo de formação; 2) estar em início de carreira - tempo de atuação inferior a cinco anos. Para tanto, divulgamos a pesquisa em duas escolas próximas à instituição sede, sendo uma particular e uma pública e em todos os semestres dos cursos de licenciatura em matemática e pedagogia da mesma. Nenhum professor das duas escolas visitadas aderiu ao projeto. Dezoito acadêmicos aderiram inicialmente à pesquisa e compareceram à primeira reunião. Desses, 16 cursavam matemática e dois pedagogia. Após definição dos horários e das possíveis datas, dez confirmaram a participação².

\section{Procedimentos para a construção de dados}

Pelo período de um ano e dois meses foram realizadas 13 sessões com aproximadamente 1 hora e 10 minutos de duração. Todas as sessões foram filmadas, após autorização prévia dos participantes ou responsáveis. Desse modo, tendo como foco a vivência em situações-problema com números fracionários e racionais e as operações aritméticas fundamentais, desenvolvemos as sessões articulando intervenção e pesquisa para o estudo das aquisições conceituais, considerando a filiação entre competências e dificuldades e, ao mesmo tempo, a análise da natureza das atividades propostas e desenvolvidas, assim como dos processos mediacionais nas interações interpessoais de modo a fomentar a análise sobre o ensinar e o aprender no EFAI/AF significando as situações de não aprendizagem nesse contexto.

Por isso, durante as sessões diferentes temas foram abordados, entre eles: a construção social e histórica dos sistemas numéricos e a sua relação com o sistema de numeração decimal, pontuando a importância do entendimento do princípio aditivo, multiplicativo e de posição; a construção e a consolidação dos conjuntos numéricos,

2. Ressaltamos que o estudo em questão foi aprovado pelo Comitê de Ética da Universidade de Brasília. Sendo também autorizado pela ISP que permitiu a utilização de suas dependências, em especial, do Laboratório de Ensino de Matemática (LEM) e de seus materiais pedagógicos e de consumo. 
focando a passagem dos números naturais para os fracionários e para os racionais; os diferentes sistemas de medidas; a lógica da notação dos algoritmos formais e alternativos das operações no contexto dos números racionais; o valor do cálculo mental e aproximado, entre outros.

Ademais, o planejamento de uma sessão aconteceu sempre após a transcrição e a análise da sessão anterior, conforme propõe Fávero (2001a). Logo, as pesquisadoras mediaram todas as atividades propostas, tomando cada participante como ser ativo e construtor de conhecimento matemático em interação com o mundo, com o outro e assumindo a conceituação matemática como defendida por Vergnaud (1990). Além disso, atentamo-nos a todos os fatos, tomando nota de acontecimentos importantes, tanto os expressos em linguagem verbal, quanto os explicitados em linguagem não verbal, além de observar e incentivar o registro da produção matemática dos participantes e de empreender a recolha desses dados para que esses não se perdessem ao longo do desenvolvimento de cada sessão.

\section{Procedimentos para análise de dados}

Em função da proposta adotada, ao término de cada sessão: 1) anotávamos nossas impressões acerca do trabalho desenvolvido em referência aos participantes e em referência a nós (formadoras de professores); 2) assistíamos à filmagem; 3) realizávamos a transcrição na íntegra de cada sessão; 4) organizávamos as tabelas de análise, tendo como objetivo o levantamento das proposições do discurso, tomadas como unidade de análise, como proposto por Fávero (2001b), assumindo a abordagem da semiótica da cultura; 5) organizávamos as notações produzidas no contexto de tais falas e montávamos um contador para essas notações; 6) analisávamos essas proposições tendo como referência os atos da fala, como propõe Fávero (2005b) a partir dos estudos de Chobral e Bromberg (1999). Em seguida, esses atos eram categorizados de acordo com as esferas propostas por esses autores - esfera da informação; da avaliação; da interação; esfera acional e contratual. Tal opção metodológica pode ser observada no Quadro 1, a seguir, que apresenta trechos da interlocução entre professores e pesquisadora. Quadros semelhantes foram produzidos tomando as interlocuções entre estudante e pesquisadora. 
Quadro 1 - Trecho das tabelas de análise geradas a partir das interlocuções entre professores e pesquisadora

\begin{tabular}{|c|c|c|c|}
\hline Transcrições & Proposições & Atos da Fala & $\begin{array}{c}\text { Categorias dos } \\
\text { Atos da Fala }\end{array}$ \\
\hline$\cdots$ & $\cdots$ & $\cdots$ & $\cdots$ \\
\hline $\begin{array}{l}\text { TRECHO } 89 \\
\text { MmE7: Ainda... Se for fazer um } \\
\text { ábaco, é melhor ainda, porque ela } \\
\text { vai estar bem... Tendo essa } \\
\text { concepção melhor ainda... De } \\
\text { questão de unidade, de dezena, de } \\
\text { centena, de milhar. }\end{array}$ & $\begin{array}{l}\text { Se construir com } \\
\text { a ajuda dela será } \\
\text { melhor ainda } \\
\text { para que ela } \\
\text { possa entender } \\
\text { unidade, dezena, } \\
\text { centena e milhar. }\end{array}$ & complementar & $\begin{array}{l}\text { Esfera da } \\
\text { interação }\end{array}$ \\
\hline $\begin{array}{l}\text { TRECHO } 90 \\
\text { FmE4: É, nesse caso, eu acho que o } \\
\text { material quadriculado é melhor } \\
\text { ainda que o dourado. Porque ele dá } \\
\text { essa possibilidade... estar cortando } \\
\text { junto com ela. “Vamos cortar dez } \\
\text { centavos". Imagina que cada } \\
\text { quadrinho daquele ( )... aquele } \\
\text { papel quadriculado que a gente faz } \\
\text { desenho... seja um centavo... ( )... } \\
\text { ou um décimo. Aí ela vai ver. }\end{array}$ & $\begin{array}{l}\text { Eu sugiro o uso } \\
\text { do material } \\
\text { quadriculado. } \\
\text { O material } \\
\text { quadriculado é } \\
\text { melhor que o } \\
\text { dourado porque } \\
\text { dá a possibilidade } \\
\text { de cortar aos } \\
\text { poucos junto com } \\
\text { a adolescente. } \\
\text { Você pode cortar } \\
\text { cada quadradinho } \\
\text { ou cortar dez } \\
\text { centavos. }\end{array}$ & $\begin{array}{c}\text { complementar } \\
\text { avaliar }\end{array}$ & $\begin{array}{l}\text { Esfera da } \\
\text { interação } \\
\text { Esfera da } \\
\text { avaliação }\end{array}$ \\
\hline
\end{tabular}

Fonte: Pina Neves (2008).

Com o intuito de organizar a apresentação e discussão dos resultados, optamos por socializá-los divididos em dois momentos: inicialmente nas sessões de intervenção com a estudante e em seguida, com os professores. Todavia, ressaltamos que os resultados das sessões com a estudante eram utilizados nas sessões com os professores e vice-versa. Além disso, tendo em conta a natureza do método adotado, apresentamos, nos dois casos, os resultados e a discussão transitando entre as sessões. 


\section{Resultados e Discussão}

\section{A pesquisa de intervenção com a estudante}

Na primeira sessão, solicitamos à estudante que respondesse, a partir do uso de estratégias que ela avaliasse pertinente, situação-problema que retratava a compra de lanche no ambiente escolar e o controle dos valores já gastos em relação a um valor total, incluindo a escrita decimal de valores menores e maiores que um inteiro. A situação provocava a reflexão sobre os conjuntos numéricos e suas notações, o cálculo mental e aproximado, assim como o uso de algoritmos alternativos e formais para as operações aritméticas fundamentais. Folhas de papel branco A4 e lápis grafite foram disponibilizados. Foi solicitado que ela não usasse borracha e que preservasse todas as notações realizadas.

Os dados da primeira sessão evidenciaram, entre outros: que a estudante não analisava o que produzia; não avaliava se suas notações eram pertinentes ao contexto da situação em questão; não apresentava suas notações inacabadas para a análise; sentia-se segura apenas para apresentar as notações que avaliava como corretas. Esses comportamentos podem indicar que a escola não tem adotado a análise das notações de escolares por parte dos professores durante a prática docente. Como também, por parte dos estudantes para a formulação de novas estratégias de ação como propõem, por exemplo, Pinto (2000), em relação à observação e à análise dos erros e Koch e Soares (2005) em relação às notações.

Durante as outras sessões novas situações-problema foram vivenciadas contemplando as situações de compra e venda, em especial, no contexto do Sistema de Pesos e Medidas (SPM) utilizando para isso encartes, embalagens vazias e instrumentos de medição. Tudo isso possibilitou a observação e avaliação das seguintes dificuldades: o uso de regras de cálculo e a incompreensão dos conceitos que as sustentavam; a aversão declarada à operação de divisão; a incompreensão da escrita decimal; a incompreensão do conjunto numérico dos números racionais; a não utilização de algoritmos alternativos para a formulação de estratégias de resolução; a dificuldade na leitura e notação da escrita decimal; ler e compreender a notação da escrita decimal presente nos encartes; em relação às unidades de medidas padronizadas. Ademais, a estudante desconhecia as conversões possíveis entre as diferentes unidades de medida e não interagia com instrumentos de medição como régua, fita métrica, entre outros. As notações seguintes exemplificam algumas dificuldades. 


\section{Figura 1 - Notações produzidas pela adolescente durante a primeira sessão}
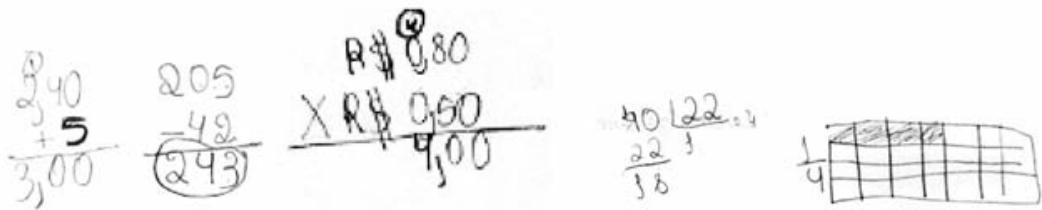

Fonte: Pina Neves (2008).

Essas evidências sugerem que a escola, de modo geral, não tem trabalhado o SPM em investigações ou em conceituações de modo a integrar campos conceituais. Ou trabalhado sem vínculo com as experiências diárias desses estudantes e de suas famílias. Tal prática desconsidera a importância da medição para a conceituação de número e exclui o estudante da compreensão de conceitos vitais para a prática consciente do consumo e da produção, como também para a atuação competente no mercado de trabalho.

Com relação à análise das interlocuções, evidenciamos que a categoria de atos da fala mais utilizada pela estudante foi a da informação e, em raros momentos, a categoria da interação e da avaliação. Entretanto, nas interlocuções pesquisadora/ estudante evidenciamos que os atos mais frequentes foram os de incitar e propor e, em menor número, os de confirmar e complementar. Tais categorias evidenciam o comportamento passivo da estudante e sinalizam que ela talvez esteja acostumada, nas relações de ensino e aprendizagem que vivencia, a perguntar pouco, a questionar pouco e a fazer apenas o que é solicitado.

A respeito da construção da atividade mediada com vistas à construção de novas competências, observamos que ocorreu a partir do momento em que mostramos a ela o quanto estava acostumada a agir sem refletir e sem compreender o conteúdo de suas ações. Ou, então, quando a convidávamos a analisar um resultado e/ou um procedimento e ela observava o quanto ele era incoerente para a situação em questão, como mostra o trecho a seguir produzido logo depois de a estudante somar 6,50 + 6,50 e produzir resultados diferentes a partir do algoritmo formal para a adição $(1,30)$ e do uso de cédulas e moedas (treze reais):

P: Treze. Ok. E dentro de um e trinta? Vai ter uma nota dessa... dentro de um e trinta? ((mostra uma cédula de 10 reais)).

C: Não.

P: Não? Vai ter o quê, dentro de um e trinta?

C: Vai ter... ((Fica pensativa)). 
P: Quantas moedas de um real têm dentro de um e trinta?

C: Uma.

P: Uma? Aí, eu vou ter mais o quê, então?

C: Mais trinta centavos. A vírgula tá errada.

Em muitos momentos das sessões, observamos que a estudante foi desafiada a vencer obstáculos epistemológicos e didáticos (Pais, 2001) a respeito dos conjuntos numéricos. Ao comparar, por exemplo, um real com cinquenta centavos surpreendeuse em validar que o algarismo 5, apesar de ter valor absoluto maior que 1, na escrita decimal seu valor relativo era menor que 1. Tal fato comprova que a aprendizagem dos números racionais supõe rupturas com ideias construídas para os números naturais, como alerta os PCN (Brasil, 1997).

Quanto à articulação situação-problema e operações, observamos que durante as três primeiras sessões a estudante se manteve presa ao pensamento aditivo e à crença de que a "multiplicação sempre aumenta" e a "divisão sempre diminui", tais certezas funcionaram, em muitos momentos, como obstáculos para o desenvolvimento das atividades. Em muitas das notações produzidas, observamos o emprego de regras sem a compreensão do seu significado, como, por exemplo, o "espaço vazio" no algoritmo formal da multiplicação; o "vai um" no da adição, “o pedir emprestado" no da subtração, o início do algoritmo de divisão pela casa da esquerda. Ou ainda, quando mostrou não compreender conceitos como: igualdade; variável; equação do primeiro grau; simétrico, entre outros. Como podemos acompanhar nas interlocuções a seguir:

P: 0 que você fez para encontrar dois positivo?

C: É porque, quando é mais... Você... Quando é menos, éh: você muda os sinais... Tem que mudar os sinais...

Suas explicações comprovam o uso de regras que nos dizem “faz assim que dá certo", sem compreensão dos conceitos que sustentam tais ações. Ademais, no caso da representação fracionária dos números racionais, novamente notamos o uso de regras, aliado ao uso de modelos didáticos:

C: (Tem que colorir), não é?

P: Tem que colorir? Como é essa história?

C: Assim... Aí, quarenta, né? Aí colore só quatro.

C: (Tinha que colorir) os quatro

C: Eu (me esqueci)... Porque lá na escola a gente não está... a gente não está estudando isso não, mas fração é assim tem que pintar. 
Tais situações mostram, ainda, um ensino pautado na transmissão de conhecimento a partir da apresentação de conteúdos separados em "caixinhas" o que prejudica que os estudantes percebam as filiações entre os diferentes conceitos. Optamos por romper tal lógica, por isso, incentivamos: a ação, o falar sobre a ação, o registrar (notação), a análise das notações, a validação de resultados, a exposição de demandas pessoais. Nesse sentido, observamos que a proposta de utilizar cédulas e moedas do Sistema Monetário Brasileiro foi decisiva na observação e na análise, por parte da estudante, da escrita decimal; para a compreensão do princípio aditivo, multiplicativo e de posição presentes no Sistema de Numeração Decimal, como também para a construção da atividade mediada. Além disso, notamos que esse espaço foi ampliado a partir do incentivo ao cálculo mental, à estimativa, à análise de notações, à criação de algoritmos alternativos e ao uso de estratégias metacognitivas.

Quanto à construção de novas competências, observamos que foi gradativa, como, por exemplo, a realização de inúmeros cálculos mentais; as ações de manusear as cédulas e moedas, registrar o valor, observar a notação e manusear novamente as cédulas e moedas foram para ela elementos de validação sobre a exatidão ou não da escrita decimal produzida e contribuíram, sobremaneira, para a compreensão dessa escrita e, para identificá-la como extensão dos princípios do Sistema de Numeração Decimal. Além disso, observamos que a análise cálculo mental/notação foi importante para a tomada de consciência dos cálculos realizados nos algoritmos formais das operações de adição, subtração, multiplicação e divisão. Ou ainda, a compreensão das diferentes representações dos racionais durante situações de medição ou de análise de embalagens associadas às conversões entre registros de representação. Como consequência, a estudante produzia com mais segurança algoritmos alternativos. Como também, desenvolvia novas estratégias de cálculo, a partir da ideia de proporcionalidade ou ainda, competências em relação aos algoritmos formais das operações. As notações a seguir mostram tais conquistas.

Figura 2 - Notações produzidas durante as atividades da quinta sessão

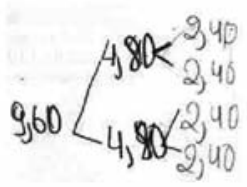

5 del,20 emtarvo is, 00 real 10 de, 0,20 contaro 2,00 verais 20 de, 0,20 entaro, 4,00 veais
23,00

46,00

$\& 12,00$

16. 24,00

1218,00 Reais
$60+6 \frac{5}{10+2+1}$

so

$\frac{0}{6}$

$\frac{5}{1}$

Fonte: Pina Neves (2008). 
Enfim, todas essas evidências apresentaram-nos, ao longo das sessões, e mais veementemente nas duas últimas, uma outra estudante. Segura; consciente de que pode se desenvolver; que fazia perguntas, questionava as atividades, expunha dúvidas e certezas conceituais, apresentava notações para análise e validação. Em outras palavras, ativa, autônoma e consciente do seu desenvolvimento.

\section{A pesquisa de intervenção com os professores}

Tendo como foco a intervenção realizada com a estudante e os conteúdos curriculares citados anteriormente, desenvolvemos cada sessão com os professores uma semana depois de realizar cada sessão com a estudante. As atividades foram organizadas em quatro grandes blocos: 1) apresentação de vídeos que retratavam a intervenção da pesquisadora com a estudante, descrita no item anterior; 2) análise das falas produzidas por eles no momento em que analisavam as competências, as dificuldades apresentadas pela estudante como também a mediação e a proposta de intervenção da pesquisadora expressa nos vídeos; 3) análise do texto "Psicologia do Desenvolvimento, didática e aprendizagem" do livro "Psicologia e Conhecimento: subsídios da psicologia do desenvolvimento para a análise de ensinar e aprender" (Fávero, 2005b); 4) análise de suas falas em contexto de leitura e interpretação do texto referido acima.

A composição do grupo de professores foi marcada por três situações: 1) a não adesão de professores que atuavam nas duas escolas próximas à ISP comprova a dificuldade em ter professores formados e em pleno exercício da função docente envolvidos em projetos de pesquisa; 2) a adesão de acadêmicos dos últimos semestres do curso de matemática e pedagogia sinaliza o interesse, muito comum entre formandos, em participar de atividades dessa natureza, e pode estar relacionada à preocupação desse público relativa à inserção e/ou manutenção no mercado de trabalho; 3) a presença das acadêmicas do curso de pedagogia apenas na parte inicial da pesquisa, pode evidenciar receio, talvez em função dos conteúdos ali tratados (Santos, 2005).

Em geral, nas interlocuções professores/pesquisadora ou professores/professores, as categorias dos atos da fala mais utilizadas foram as da informação, bem como a interação em menor número a avaliação. Nas interlocuções pesquisadora/professores, os atos mais frequentes foram os de incitar, de propor e, em menor número, os de confirmar e complementar. 0 baixo uso dos atos de interação, por parte dos professores, sinaliza que suas falas foram marcadas pela concordância, complementação e confirmação. Em raros momentos esse fato foi alterado, e divergências foram declaradas e debatidas entre eles, apesar das provocações constantes da pesquisadora. Na segunda sessão, por exemplo, FmE4 discordou da relevância dada por FmE3 ao material 
dourado e, em outro momento, criticou a baixa quantidade de moedas de um centavo ofertadas à estudante. Na quinta sessão, FmE4 e FmE2 contestaram a seguinte fala de MmE7: “Assim... Vamos... Leia um pouquinho, leia o conteúdo, faça os exercícios... Pega o exercício que foi feito em sala, refaça... Uma vez, duas vezes, tenta fazer o exercício."

A menor quantidade de atos como contestar, criticar e desafiar pode indicar, por exemplo: o desconhecimento dos assuntos em discussão; a não vivência em situações de avaliação e exposição de argumentos; desinteresse em se inteirar de tais discussões; o receio em socializar suas análises, entre outros. 0 que em nossa análise pode indicar a natureza das mediações vividas pelos professores em seus cursos de formação inicial.

A atividade mediada foi construída de modo a instigar, propor e incitar o grupo a observar, a falar, a questionar, a debater e a propor. Todavia, em muitos momentos, enfrentamos dificuldades em coordenar as perguntas dirigidas ao grupo, visto que eles não as respondiam e inseriam elementos nem sempre relacionados às perguntas formuladas. Tais dificuldades foram minimizadas por meio da mediação constante da segunda autora desse estudo, o que corrobora a necessidade de análise processual das sessões (Fávero, 2001a), além de exemplificar que a construção de novas competências para a prática da pesquisa acontece, também, ao longo da execução do estudo (Pina Neves, 2010). Os dados evidenciam a falta de experiência do grupo em trabalhar com atividades de avaliação de dificuldades e competências de um estudante real a partir de suas ações e de suas notações. Tal constatação pode refletir o lugar que a interpretação das notações, por parte de estudantes e professores, ocupa nos cursos de formação de professores para a educação básica. E sinaliza que, nesses cursos, a prática docente de matemática não tem sido construída com base nessas análises.

Tais dados corroboram estudos em formação de professores que ensinam matemática que relatam a dificuldade vigente nos cursos de equilibrar: teoria e prática, conteúdo e método, disciplinas de formação específica e disciplinas de formação para a docência. Além disso, observamos que os professores insistiram em abandonar a produção da estudante em debate e eleger um estudante, um professor ou uma escola genérica para as análises. A tentativa de todos de falar com base nas informações do senso comum imprimiu, em muitos trechos, falas generalizadas a respeito de ninguém.

Em síntese, os professores descreveram como dificuldades da estudante: a compreensão da escrita de decimais e dos algoritmos formais das operações básicas. Como competências: manuseio de cédulas e moedas; realização de agrupamentos e trocas a partir do manuseio das moedas; cálculo a partir do manuseio de cédulas e moedas. Em muitos momentos os professores evidenciaram suas contradições no que se refere ao discurso sobre a prática docente e a prática. Inicialmente, avaliaram o uso 
de cédulas e moedas como elemento desencadeador de reflexão e de observação pela estudante a respeito das notações produzidas por ela. Além disso, avaliaram o desenvolvimento da estudante das primeiras sessões para as demais como relacionado a três situações: 1) o fato de as sessões não terem fim avaliativo deixou a estudante mais à vontade para expor perguntas e dúvidas; 2) a natureza da atividade mediada que possibilitou a discussão e a compreensão de regras; e 3) a avaliação positiva da pesquisadora quanto à capacidade de desenvolvimento da estudante. Posteriormente, afirmam que a docência no EFAl deve ser desenvolvida sempre com o apoio de material "concreto"; que o uso de termos como "passa para lá"; "pedir emprestado"; "vai um", entre outros, é comum na fala de professores e são inadequados; que o uso de termos corretos deve ocorrer desde os anos iniciais até a formação superior e que esse uso e seus significados deveriam ser discutidos nos cursos de formação de professores, tanto na pedagogia quanto na matemática. Por fim, quando simularam explicações, demonstraram que muitos ainda eram usuários de regras e dos mesmos termos julgados por eles inadequados. Na terceira sessão, por exemplo, quando MmE8 simulou no quadro como explicaria a divisão 327 por 42 .

MmE8: Então, tem que ser sete. Sete dá. [...] sete vezes dois, vai um... sete vezes quatro, vinte e oito; com um, vinte e nove... subtrai-se... sete menos quatro, três... dois menos nove não dá, pega-se emprestado... (lfala rindol) fica doze... doze por nove, três... aqui ficou dois... dois menos dois, zero.

Tais falas muito se aproximavam das utilizadas pela estudante em suas explicações, e sinalizam que o uso de procedimentos e/ou regras que indicam "faz assim, coloca aqui, isola, muda" é comum ao discurso de estudantes e professores da educação básica. Tais resultados são similares aos apresentados em Fávero e Soares (2002).

As propostas de ação sugeridas pelo grupo apontam para a utilização de material didático, comumente intitulado por eles de material "concreto". Observamos que as propostas são genéricas, com descrições rápidas de ações, sem mencionar como desenvolveriam tais propostas e com que finalidade. 0 que sugere que eles nunca ou pouco utilizaram tais materiais em suas aulas ou elaboraram alguma proposta de ação tendo-os como instrumento mediador, como já alertavam Fávero e Pina Neves (2006) em estudo com pedagogas. Tais evidências, novamente, colocam em análise a natureza do trabalho que vem sendo realizado nos cursos de formação de professores e o modo como eles têm discutido a prática docente e como têm estruturado seus estágios.

Os professores, em especial aqueles que atuavam em sala de aula, foram provocados a observar e a analisar suas práticas. Contudo, alguns não aceitaram o desafio e se 
esquivaram da oportunidade de socializar, interpretar e discutir suas práticas no âmbito da pesquisa. 0 grupo foi unânime em avaliar que encontrou dificuldades em ler o texto proposto, em função do pouco estudo em psicologia durante o curso de formação, como também pela própria dificuldade de leitura. Todavia, foram decisivos nas análises em prol da construção de novas práticas de ensino e de aprendizagem da matemática.

Observamos, também, no conjunto das sessões, que muitos fatos causaram desconforto aos professores, entre eles: a socialização das transcrições na íntegra das sessões expõe falas, ações e paradigmas pessoais: manipular a vírgula é saber colocar no local correto; ela não soube montar, montar significa passar da linguagem do português para a matemática; concreto é quando você consegue tocar; as simulações de explicações; a comprovação que muitos eram usuários de regras sem compreendê-las;

Esses desconfortos podem explicar, por exemplo, a ausência de MmE8 após o episódio da explicação no quadro, a participação de FmE5 e FmE6 somente em algumas sessões e o silêncio de FmE3.

Nas sessões finais, alguns integrantes do grupo, em especial, FmE1, FmE2 e FmE4, avaliaram suas experiências como discentes da educação básica e do ensino superior. Tais avaliações podem ser acompanhadas na fala: FmE2 “... a gente não sabe pensar logicamente sobre os números..." ou ainda, na dúvida levantada entre elas de que seriam usuárias de regras também no ensino superior, FmE1: reproduzindo regras sem entender a lógica. Além disso, elas avaliaram, com o apoio dos demais, de modo informal, que o modelo didático <definição-exemplos-exercícios> é o mais usado pela maioria dos docentes das disciplinas de conteúdo específico da matemática no curso que frequentam. E que as propostas didáticas defendidas nas disciplinas de estágio supervisionado, como avaliação processual e formativa, práticas de ensino investigativas, respeito à produção dos estudantes, entre outras, não são vivenciadas por eles nas disciplinas específicas (Fiorentini, 2003). Interpretamos que tais denúncias, após o término da sessão, revelam, ainda, o receio dos professores gravarem as avaliações que fizeram sobre a prática docente de seus professores (formadores de professores).

No que se refere às representações sociais, a matemática aparece na fala dos professores, inicialmente, associada à ideia de ciência clássica, positivista, que, na análise de Fávero (2005b, p. 55), fundamenta uma "prática que procura transmitir as teorias científicas das diferentes áreas do conhecimento... por isso o verbo mais usado pelos professores, ao se referir à sua prática de ensino, é o verbo passar". Contudo, os dados da quarta, quinta e sexta sessão, principalmente, aqueles que comprovam as consequências da prática docente a partir da ótica da transmissão, sugerem que essa premissa começou a ser questionada por alguns dos professores. 
Nesse sentido, evidenciamos que a intervenção psicopedagógica desenvolvida nesta pesquisa propiciou a todos os professores acessar o significado de suas práticas, a reflexão sobre sua reformulação. Entendemos que as resistências apresentadas por alguns refletem a complexidade dessa reformulação.

\section{Considerações Finais}

Os resultados discutidos nos itens anteriores evidenciam que a proposta teóricometodológica de Fávero (2005a, 2007a, 2009) para a pesquisa de intervenção psicopedagógica é pertinente para a produção de conhecimento na pesquisa em educação matemática e em psicologia da educação matemática, uma vez que através dela se prova: o papel da atividade mediação, a importância da representação e notação na prática de professores e estudantes; o papel do currículo e da prática de avaliação; as concepções sobre a matemática e sobre a conceituação matemática; a formação inicial e continuada em matemática e pedagogia, a prática docente nesses cursos; 0 papel da pesquisa na formação do professor. Em resumo, sua pertinência está justamente no fato de que ela nos evidencia, independente da faixa etária com a qual se trabalha, dados sobre o ensinar e o aprender matemática nos anos iniciais.

No contexto da organização dos espaços de mediação e de ação, pontuamos que o LEM constituiu espaço privilegiado para a criação e desenvolvimento de práticas investigativas a partir do uso de instrumentos mediadores (convencionais e não convencionais), como mostram Varizo (1997), Lorenzato (2006) e muitos outros. A análise das atividades mediadas ao longo das sessões de intervenção mostrou que a compreensão dos objetos matemáticos depende de um sistema de representação semiótica, por meio do qual seja possível realizar seu tratamento; que as representações semióticas têm um papel significativo na estruturação do pensamento, refletindo a relação dinâmica e interativa entre notação e representação (Koch; Soares, 2005).

Os resultados salientam que a construção do conhecimento não é um processo linear. Ao contrário, é complexo, demorado, com avanços e retrocessos, continuidades e rupturas. Vimos, também, que o conhecimento prévio da estudante e dos professores foi determinante nos processos de interação com os conteúdos em questão e que, em alguns casos, impôs obstáculos (Pais, 2001). Entendemos que compreender a conceituação em matemática, assim como proposto por Vergnaud (1990), contribuiu para o acompanhamento e a análise das produções dos participantes, uma vez que possibilitou observar que as situações dão sentido ao conceito, os invariantes operatórios constituem seu significado e as representações simbólicas o seu significante.

Os resultados também questionam o Sistema de Avaliação da Educação Básica, tendo em vista que as dificuldades apresentadas pela estudante referem-se, em grande 
parte, a conceitos amplamente trabalhados desde o segundo ano do EF. Os dados provocam-nos a inferir que a escola tem adotado uma falsa prática de avaliação da aprendizagem e uma não avaliação do ensino, uma vez que essa não tem avaliado o desenvolvimento conceitual dos estudantes, tampouco a prática docente dos professores, como também as concepções de ensino e aprendizagem que sustentam tais práticas. 0 que é contraditório, visto que "A avaliação é mais que a mediação das respostas "certas" ou "erradas" do aluno, é uma etapa que alimenta a sua própria prática didática” (Fávero, 2009, p. 22, tradução nossa).

Em resumo, o estudo denuncia a prática ainda vigente que concebe a formação docente, a partir do modelo da racionalidade técnica, uma vez que se observa: a separação entre teoria e prática na preparação profissional; a prioridade dada à formação teórica em detrimento da formação prática; e a concepção da prática como mero espaço de aplicação de conhecimentos teóricos, sem um estatuto epistemológico próprio (Moreira; David, 2005). De certa forma, os resultados das sessões com os professores, aliados ao fato de alguns deles já atuarem como docentes na educação básica, comprovam o que acompanhamos nos últimos anos: aumento significativo no número de professores para uma população escolar igualmente crescente. 0 que provoca, a cada dia, a criação indiscriminada de cursos de licenciatura em matemática e pedagogia em faculdades de pequeno e médio porte e a expansão do ensino superior privado, além da (manutenção) permissão do exercício profissional por pessoas não habilitadas (professores leigos). Além disso, observamos no grupo de professores que nem todos têm a carreira docente como opção para o futuro depois da graduação. Isso sugere que a escolha da licenciatura está relacionada, em muitos casos, à falta de oportunidades para acessar outras carreiras, dando margem para a leitura de que essa é uma escolha de segunda opção, uma profissão-refúgio, como definiu Nóvoa (1992). Ou, como define Imbernón (2005) uma semiprofissão.

\section{Referências}

BERTONI, Nilza Eigenheer. Compreendendo a adição e a subtração. In: SALGADO, Maria Umbelina Caiafa; MIRANDA, Glaura Vasques de. (Org). Guia de Estudo. Módulo 2. Volume 2. Belo Horizonte: Secretaria de Estado da Educação de Minas Gerais, 2002. p. 48-81.

BONFIM, Regina Andréa Fernandes. Aquisição de conceitos matemáticos na Sala de Recursos: relato de uma pesquisa de intervenção. Brasília: Universidade de Brasília, 2006. Dissertação (Mestrado em Psicologia).

BRASIL, Ministério da Educação e do Desporto. Secretaria de Educação Fundamental. Parâmetros Curriculares Nacionais: Matemática. Brasília, DF, 1997. 
CELESTE, Letícia Barcaro. A Produção Escrita de alunos do Ensino Fundamental em questões de matemática do PISA. Londrina: Universidade Estadual de Londrina, Londrina, 2008. Dissertação (Mestrado em Ensino de Ciências e Educação Matemática).

CHABROL, Claude; BROMBERG, Marcel. Préalables à une classification des actes de parole. Psychologie Française, v. 44, n. 4, p. 291-306, 1999.

FÁVERO, Maria Helena. Psicologia do Conhecimento. Brasília: Editora Universidade de Brasília, 1993.

Regulações cognitivas e metacognitivas do professor: uma questão para a articulação entre a psicologia do desenvolvimento adulto e a psicologia da educação matemática. In: SIMPÓSIO BRASILEIRO DE PSICOLOGIA DA EDUCAÇÃO MATEMÁTICA, 1., Sociedade Brasileira de Psicologia da Educação Matemática, Sociedade Brasileira de Educação Matemática (Orgs.). Anais: trabalhos completos. Curitiba: Editora da UFPR, p. 187-197, 2001a.

“E se fosse comigo?": os adolescentes frente a uma situação hipotética de gravidez. Universitas Psicologia. Brasília, v. 2, n. 2, p. 62-81, 2001 b.

A aquisição do conhecimento matemático em condições especiais: da pesquisa para o fundamento da prática de ensino. In: ENCONTRO DE PESQUISA EM EDUCAÇÃO DA REGIÃO CENTROOESTE, 7., Anais... Goiânia, GO, 2004.

Desenvolvimento psicológico, mediação semiótica e representações sociais: por uma articulação teórica e metodológica. Psicologia: Teoria e Pesquisa, v. 21, n. 1, p. 17-25, 2005a.

. Psicologia e Conhecimento. Subsídios para a análise do ensinar e aprender. Brasília: Editora Universidade de Brasília, 2005b.

Semiotic mediation, psychological development process and social representations: toward a theoretical and methodological integration. Europe's Journal of Psychology, v. 9, n. 9, 2007a.

Paradigme personnel et champ conceptuel: implications pour les situations didactiques. Dans: MERRI, Maryvonne (Org.). Activité Humaine et Conceptualisation. Toulouse, France: Presses Universitaires du Mirail, 2007b. p. 625-634.

Os fundamentos teóricos e metodológicos da Psicologia do Conhecimento. In: FÁVERO, Maria Helena; CUNHA, Célio (Coord.). Psicologia do Conhecimento. 0 diálogo entre as ciências e a cidadania. Brasília: UNESCO, 2009

A pesquisa de intervenção na psicologia da Educação Matemática: aspectos conceituais e metodológicos. Educar em Revista (Impresso), v. 1, p. 47-62, 2011 a.

A Pesquisa de Intervenção na Construção de Competências Conceituais. Psicologia em estudo, Maringá, 2011b. No prelo.

PINA NEVES, Regina da Silva. A divisão e os racionais: como os professores avaliam a produção dos alunos. In: REUNIÃO DE DIDÁTICA DA MATEMÁTICA DO CONE SUL, 7., 2006, Águas de Lindóia, SP. SBEM (Org.). Anais Coordenação do Evento. São Paulo, SP: PUC-SP, 2006.

Division and rational numbers in research: bibliographic revision, analysis and theoretic-methodological proposal. In: CONFERENCIA INTERAMERICANA DE EDUCACIÓN MATEMÁTICA, 12., 2007, Santiago de Querétaro, Qro. Anais... Santiago de Querétaro, Qro.: edebéméxico, 2007.

Competências para resolver problemas e para analisar a resolução de problemas: um estudo junto a professores, licenciandos, pedagogos e psicólogos. Psicologia Escolar e Educacional. Campinas, Associação Brasileira de Psicologia Escolar e Educacional, v. 13, p. 113-124, 2009. 
.; SOARES, Maria Tereza Carneiro. Iniciação escolar e a notação numérica: Uma questão para o estudo do desenvolvimento adulto. Psicologia: Teoria e Pesquisa. Brasília, Instituto de Psicologia, Universidade de Brasília, v. 1 8, n. 1, p. 43-50, 2002.

FIORENTINI, Dario. Formação de professores de matemática: explorando novos caminhos com outros olhares. São Paulo: Mercado das letras, 2003.

IMBERNON, Francisco. Formação docente e profissional: formar-se para a mudança e a incerteza. 5. ed. São Paulo: Cortez, 2005.

KOCH, Nancy Terezinha Oldenburg e SOARES, Maria Tereza Carneiro. (2005). 0 professor, seus alunos e a resolução de problemas de estrutura aditiva. In: MORO, Maria Lúcia Faria; SOARES, Maria Tereza Carneiro. (Orgs.), Desenhos, palavras e números: as marcas da matemática na escola (pp.145-182). Curitiba, Editora da UFPR.

LORENZATO, Sérgio (Org.). O Laboratório de Ensino de Matemática na Formação de Professores (coleção formação de professores). São Paulo: Autores Associados, 2006.

MOREIRA, Plínio Cavalcanti; DAVID, Maria Manuela Martins Soares. A formação matemática do professor: licenciatura e prática docente escolar. Belo Horizonte: Autêntica, 2005.

MORO, Maria Lúcia Faria; SOARES, Maria Tereza Carneiro. Desenhos, palavras e números: as marcas da matemática na escola. Curitiba: Ed. Da UFPR, 2005.

NóVOA, António. Formação de professores e profissão docente. In: NóVOA, António. (Coord.). Os professores e a sua formação. Lisboa: Dom Quixote, 1992. p. 13-33.

NUNES, Terezinha; BRYANT, Peter. Crianças fazendo matemática. Porto Alegre: Artes Médicas, 1997.

SANTOS, dos Aparecido. 0 conceito de fração em seus diferentes significados: um estudo diagnóstico junto a professores que atuam no ensino fundamental. Pontifícia Universidade Católica, São Paulo, 2005. Dissertação (Mestrado).

PAIS, Luiz Carlos. Didática da Matemática: uma análise da influência francesa. Belo Horizonte: Autêntica, 2001.

PINA NEVES, Regina da Silva. A divisão e os números racionais: uma pesquisa de intervenção psicopedagógica sobre o desenvolvimento de competências conceituais de alunos e professores. Universidade de Brasília, Brasília, 2008. Tese (Doutorado em Psicologia).

(2010). Opção teórico-metodológica: reflexão e tomada de decisão no caminhar da pesquisa. In Jaqueline Araújo Civardi, João Pedro Machado Ribeiro e Marcos Antônio Gonçalves Júnior (Orgs.). Como nos tornamos pesquisadores? Bastidores de pesquisas em Educação Matemática. Curitiba, Editora CRV, p. 59-68.

PINTO, Neuza Bertoni. O erro como estratégia didática. Campinas: Papirus, 2000.

SAIZ, Irma. Dividir com dificuldade ou a dificuldade de dividir. In: PARRA, Cecília; SAIZ, Irma. (Orgs.). Didática da matemática: reflexões psicopedagógicas. Porto Alegre: Artes Médicas, 1996. p. 11-25.

VARIZO, Zaíra da Cunha Melo. Laboratório de educação matemática. Uma experiência, um desafio. Revista de Extensão Universitária, UFG, Ano I, n. 2, p. 35-46, 1997.

VERGNAUD, Gérard. La théorie des champs conceptuels. Recherches en Didactique des Mathématiques, v. 10, p. 133-170, 1990.

Recebido em setembro de 2011.

Aprovado em janeiro de 2012. 
Regina da Silva Pina Neves, doutora em Psicologia e mestre em Educação pela Universidade de Brasília. Professora e orientadora do curso de especialização em psicopedagogia do Instituto de Psicologia da Universidade de Brasília. Publicações recentes: La intervención psicopedagógica como opción teórico-metodológica para la formación inicial de profesores de matemática (Federación Iberoamericana de Sociedades de Educación Matemática, 2011); Como nos tornamos pesquisadores? Bastidores de pesquisa em Educação Matemática (Curitiba, 2010). E-mail: reginapinadgmail.com

Maria Helena Fávero, doutora em Psicologia pela Université de Toulouse II (Le Mirail). Professora associada III; professora e orientadora do programa de Pós-Graduação em Processos de Desenvolvimento Humano e Saúde, do Departamento de Psicologia Escolar e do Desenvolvimento, IP/UnB. Bolsista de produtividade em pesquisa do CNPq. Publicações recentes: Psicologia do gênero: Psicobiografia, sociocultura e transformações (Curitiba: Editora da UFPR, 2010); A pesquisa de intervenção na psicologia da Educação Matemática: aspectos conceituais e metodológicos (Educar em Revista, n. 1, p. 47-62, 2011). E-mail: faveromhabrturbo.com.br 